\title{
Mya Gosling, William Shakespeare e Bobby Pickett: diálogos possíveis em The (Shakespearean) Monster Mash
}

\author{
Rebeca Pinheiro Queluz
}

\section{Mya Gosling e os quadrinhos do blog "Good Tickle-Brain"}

Neste artigo nos propomos a analisar uma história em quadrinhos do blog "Good Tickle-Brain", da ex-bibliotecária da University of Michigan Graduate Library, hoje cartunista em tempo integral, Mya Lixian Gosling. A autora, que começou a divulgar o seu trabalho no Facebook e, subsequentemente, criou um blog e algumas contas em outras redes sociais, como o Twitter e o Instagram, para se promover, traz como tema principal de seus quadrinhos as peças de William Shakespeare. As atualizações nesses domínios ocorrem pelo menos duas vezes na semana, às terças e quintas.

O diálogo com a obra shakespeariana é estabelecido desde o título do blog, que foi concebido a partir de um monólogo de Falstaff (Henrique $V$, ato 2, cena 4): “-Peace, good pint-pot. Peace, good tickle-brain!”. Segundo a quadrinista,

In Act 2, Scene 4, Falstaff is play-acting as King Henry IV, only his grandiose delivery keeps getting punctuated by interjections from Mistress Quickly, so he turns to her and says "Peace good pint-pot, peace good tickle-braine." I've always thought it was a fantastically charming insult, and have thus appropriate for my own nefarious purposes. Shakespeare won't mind. (GOSLING, 2018)

Nesse sentido, a cartunista optou por uma expressão que capturasse o humor shakespeariano e que combinasse com o estilo do seu trabalho.

Gosling se tornou célebre, sobretudo, devido a uma seção em seu blog intitulada Three-panel plays. Brincando com a ideia de que as pessoas 
não têm tempo (ou têm preguiça) para ler as peças do bardo inglês, a quadrinista resolveu sintetizá-las em tiras de três quadros, como se pode observar na Figura 1. Nela, selecionamos as peças a que Gosling fará referência em The (Shakespearean) Monster Mash, objeto deste trabalho.

JULIUS CAESAR (in 3 Panels)
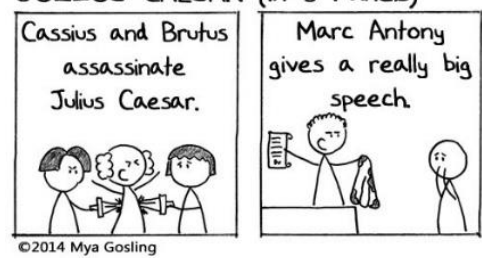

RICHARD III (in 3 Panels)

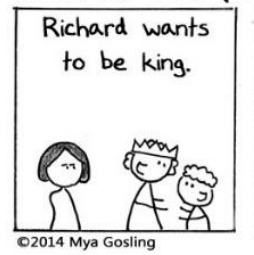

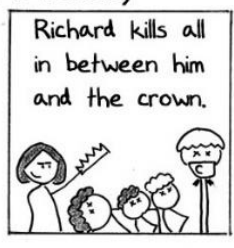
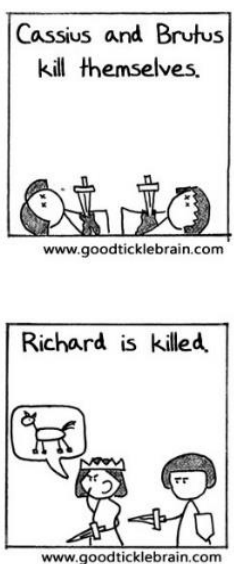

HAMLET (in 3 Panels)
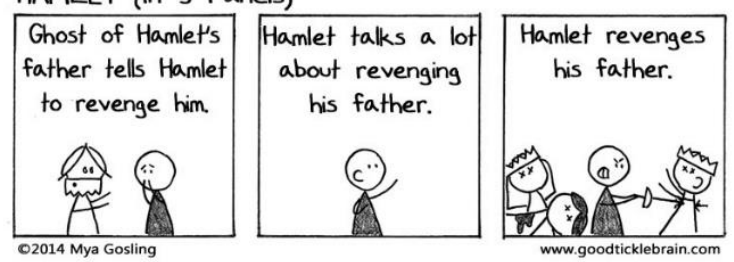

MACBETH (in 3 Panels)
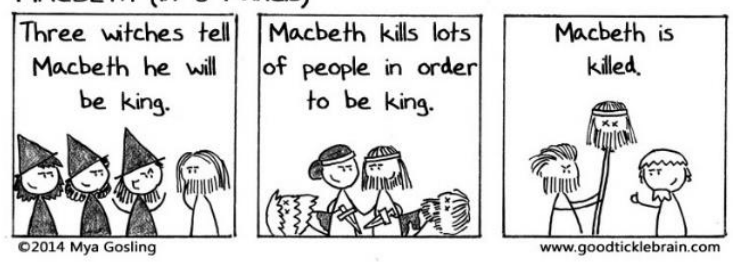

Figura 1: Júlio César, Hamlet, Ricardo III e Macbeth em 3 quadros.

Fonte:<http://goodticklebrain.com/shakespeare-index/\#/three-panel-plays/>.

Ao condensar essas obras, a autora recupera algumas das cenas/falas icônicas das peças (como se pode ver no terceiro quadro de Ricardo III), realiza comentários críticos (como se observa no segundo quadro de Hamlet), destaca elementos que chamaram sua atenção (como o protagonismo de Cássio e Brutus e o longo discurso de Marco Antônio em Júlio César), além de realçar pontos fulcrais (como a profecia das bruxas e a decisão de tornar verdadeiras as profecias em Macbeth).

"Good Tickle Brain" dispõe, ainda, de outras seções, igualmente interessantes e com muitas sacadas de humor: General Shakespeare, Shakespearean what-ifs, Stratford Festival e Miscellaneous. Na primeira seção, Gosling se propõe a imaginar as personagens shakespearianas utilizando Instagram e Whatsapp e supõe alguns problemas de comunicação a partir dos desentendimentos gerados por essas tecnologias. Nesse sentido, a autora problematiza não apenas as múltiplas possibilidades de recriação dos textos, como as próprias mídias e as linguagens aí constituídas. Também apresenta paródias musicais de Hamlet, Macbeth, O conto de 
inverno, Sonho de uma noite de verão e Como gostais. Além disso, trabalha com temas como Shakespeare e política, relaciona as peças do dramaturgo a eventos mundialmente celebrados, como a Copa do Mundo, a datas especiais (como o Dia dos Namorados, Natal, Halloween, Thanksgiving, Ano Novo) e ao ensino (Figura 2).

SHAKESPEAREAN SELFIES, part 1
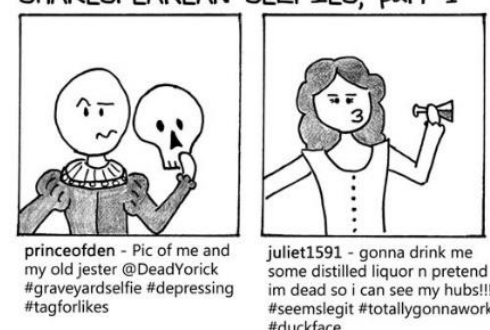

juliet1591 - gonna drink me im dead so i can see my hubs!! \#duckface

SHAKESPEAREAN VALENTINES, part 1
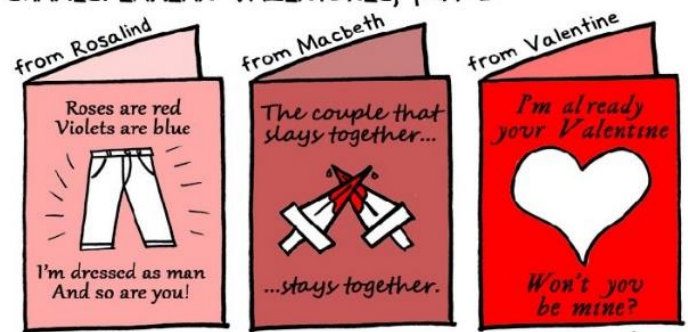

SHAKESPEAREAN VOCABULARY, part 1
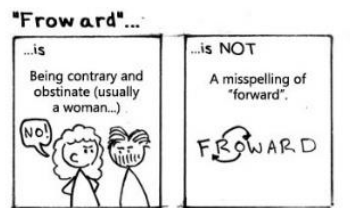

"Chuck"...
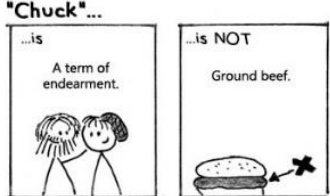

THE FROZEN WINTER'S TALE, part 1

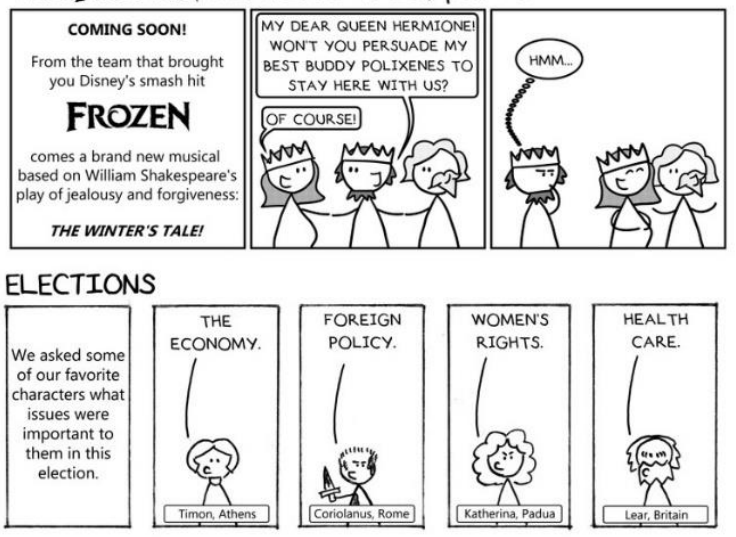

THE SHAKESPEARE WORLD CUP 2014

GROUP A

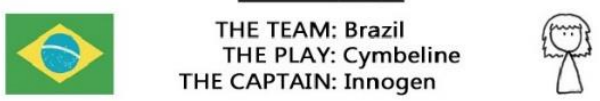

WHY IT WORKS: Cymbeline treads a rocky path to its conclusion, with frequent instances of violence, jealousy and betrayal threatening to derail its predestined happy
ending. However, the final scene is one of the most entertaining and ending. However, the final scene is one of the most entertaining and
satisfying resolutions to a play ever. Can Brazil overcome its social and satisfying resolutions to a play ever. Can Brazil overcome
political problems to achieve the ultimate victory at home? OMENS: Innogen plays host to lachimo, an Italian who ends up framing her for adultery, which
almost gets her killed. Brazil and Italy could meet in the quarter-finals. Will the hosts fall to Italian trickery?

Figura 2: Excertos tirados da seção General Shakespeare de "Good Tickle-Brain", de Mya Gosling.

Fonte:<https:/goodticklebrain.com/shakespeare-index/\#/general-shakespeare/>.

Já na segunda seção, a cartunista oferece linhas do tempo alternativas para momentos cruciais de Hamlet, Júlio César e Macbeth. Tratase de livretos que podem ser impressos e que contêm no título a questão " $\mathrm{E}$ se...?": "What if Hamlet wasn't so darn wishy-washy?" (Figura 3); “What if Caesar listened to what everyone was trying to tell him?"; "What if Macbeth wasn't so darn impatient?". 


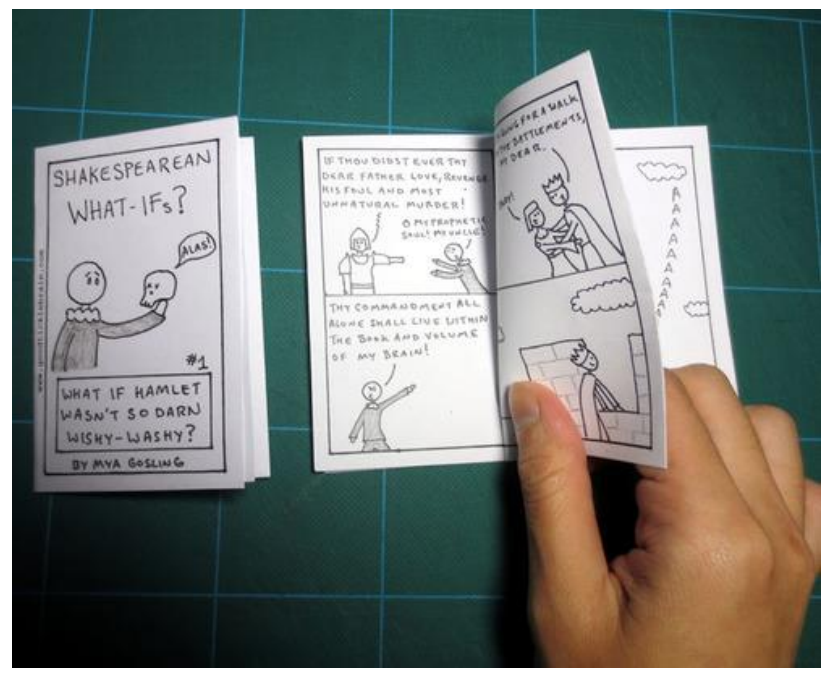

Figura 3: Mini-comic impresso de Hamlet.

Fonte:<https://goodticklebrain.com/shakespeare-index/\#/shakespearean-what-ifs/>.

Por outro lado, em Stratford Festival (of Canada) e em Miscellaneous, Gosling faz comentários e resenhas sobre as produções teatrais que vem acompanhando de perto desde 2013, apresenta situações do seu dia a dia, exibe tirinhas sobre bibliotecas, mini-comics (com temática variada), publica quadrinhos sobre seus hobbies (como escalada). Em síntese, ao mesmo tempo em que a cartunista lida constantemente com processos de leitura, ela analisa e reconstrói a interpretação das personagens, das peças shakespearianas e das performances teatrais com as quais teve contato, abrindo espaço para mostrar aos leitores um pouco do seu cotidiano. 


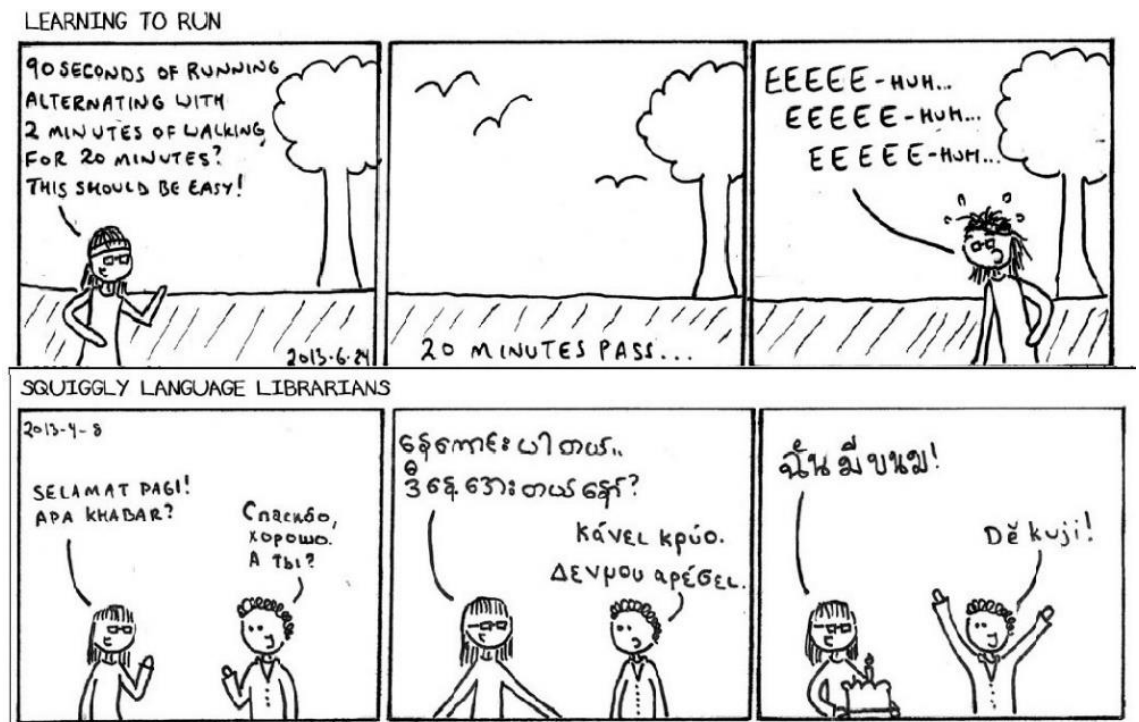

SF2014 DAY 3: SNAPSHOTS
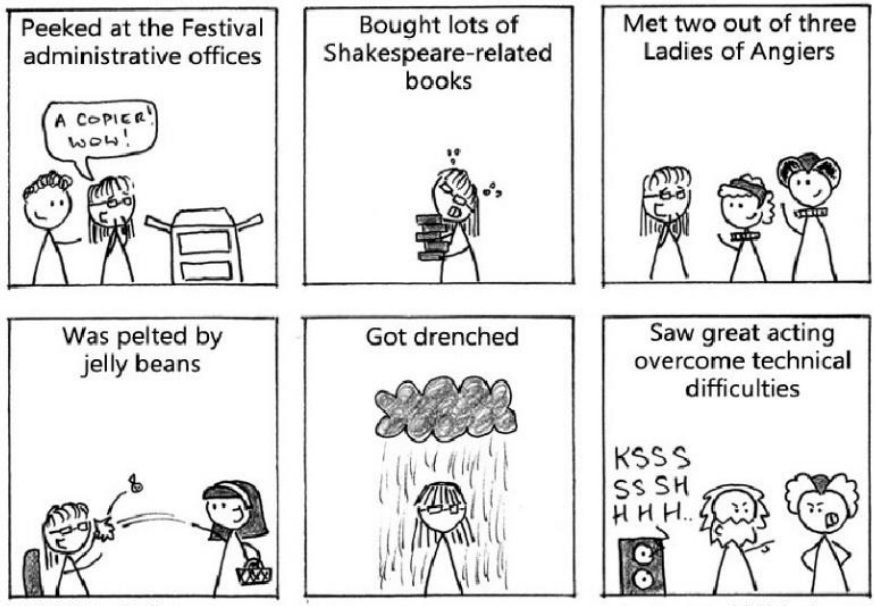

Figura 4: Seções Micellaneous (Everyday Tales e Libraries) e Stratford Festival de "Good Tickle-Brain".

Fonte: $<$ https://goodticklebrain.com/>.

Por fim, a quadrinista concentra a maior parte do seu esforço e energia na adaptação das peças shakespearianas propriamente ditas. Sua ideia é retratar as cenas uma a uma. Há espaço para a representação das Dramatis Personae (com direito a comentários irônicos sobre o papel de certas personagens ou sobre sua personalidade), para a contagem de mortes e casamentos ao longo da história (The death and marriage totals for $<$ name of the play>), para a ilustração do relógio de mortes (Death Clock) e do 
resumo da peça em uma página e para as tirinhas Stand-Alone, que se remetem de algum modo a determinada peça.

Embora cada uma das seções do blog de Mya Gosling seja intrigante para discutir os processos de apropriação, adaptação e tradução literária para outras linguagens midiáticas, neste artigo buscamos concentrar nossos esforços sobre uma história em quadrinhos intitulada The (Shakespearean) Monster Mash, criada a partir de personagens de quatro peças shakespearianas (previamente mencionadas) - Júlio César, Hamlet, Macbeth e Ricardo III - e da música The Monster Mash, composta por Leonard Capizzi e Bobby Pickett. Isto posto, dialogaremos teoricamente com as noções de transposição intermidiática, intertextualidade e paródia para, em seguida, analisarmos nosso objeto de estudo.

\section{Criando uma ponte para abordar o trabalho de Mya Gosling: breve exposição sobre transposição intermidiática, intertextualidade e paródia}

Segundo Irina Rajewsky, intermidialidade se refere ao cruzamento das fronteiras entre as mídias. No sentido restrito do termo, em um artigo intitulado "Intermidialidade, intertextualidade e remediação: uma perspectiva literária sobre a intermidialidade" a teórica propõe três categorias distintas para o termo: transposição intermidiática, combinação de mídias e referências intermidiáticas, das quais duas nos interessam aqui: a combinação de mídias e a transposição intermidiática.

Na primeira, o que Rajewsky chama de qualidade intermidiática é determinada "pela constelação midiática que constitui um determinado produto de mídia, isto é, o resultado ou o próprio processo de combinar, pelo menos, duas mídias convencionalmente distintas ou, mais exatamente, duas formas midiáticas de articulação" (RAJEWSKY, 2012, p. 24). Essa categoria abrange, segundo a autora, fenômenos como a ópera, o filme, o teatro, a performance, os manuscritos com iluminuras, as instalações e os quadrinhos.

Na segunda, por sua vez, a qualidade intermidiática está relacionada ao "modo de criação de um produto, isto é, com a transformação de um determinado produto de mídia (um texto, um filme, etc.) ou de seu substrato em outra mídia" (RAJEWSKY, 2012, p. 24). É, 
conforme a teórica, um processo "genético" de transformar um texto composto em outra mídia segundo as possibilidades materiais e as convenções vigentes dessa nova mídia. Nesse sentido, de acordo com Rajewsky, a quadrinização literária pode ser considerada uma transposição intermidiática, por envolver um processo adaptativo de transformação de um gênero narrativo literário para a história em quadrinhos, que envolve imagens e palavras em uma sequência de contiguidade e consecutividade narrativa.

Como ressalta Rafael Jose Bona,

ao se adaptar de uma mídia para outra, ocorrem, muitas vezes, mudanças de gêneros, idiomas e, neste caso, as questões culturais que são transpostas para cada regionalidade. Tudo levando a um processo transcultural e a história adaptada passa a fazer parte de uma indigenização em novo contexto, em que se mudam os significados (BONA, 2017, p. 125).

Mya Gosling, ao criar The (Shakespearean) Monster Mash, opera com três mídias distintas - teatro, música e quadrinhos - e estabelece diálogos profícuos entre elas, como veremos mais adiante.

Por seu turno, intertextualidade concerne à interação entre textos, ao entrecruzamento de textos, à ressignificação do que já foi dito. Nessa perspectiva, o texto abre espaço para o diálogo com diversas outras obras, oferecendo uma visão de mundo multifacetada e caleidoscópica. Considerando o caráter autorreflexivo da literatura e, de maneira mais abrangente, da obra de arte, o significado de uma obra se estabelece através de sua relação com outros textos, com a tradição literária/artística existente.

A partir das ideias de Mikhail Bakhtin, Julia Kristeva elaborou um ensaio chamado "Word, Dialogue, and Novel", publicado em 1966, para discutir o conceito de intertextualidade. Nele, a autora destaca que a estrutura literária não existe por si só; pelo contrário, é gerada em relação à outra estrutura, numa “interseção de 'superfícies textuais' que levam em consideração não apenas o escritor como também o leitor e o contexto cultural contemporâneo e passado da obra" (PEREIRA, 2015, p. 22). Na obra denominada Introdução à semanálise, Kristeva afirma que "todo texto se constrói como mosaico de citações, todo texto é absorção e transformação 
de um outro texto" (KRISTEVA, 1974, p. 64). Assim, reforça-se o pressuposto de que nenhum texto é original, neutro ou puro, porque sempre fará remissão a outros textos. Os textos são construídos a partir de uma série de discursos já existentes. Eles surgem de um trabalho de assimilação e de transformação.

Nessa mesma direção, Patrick Charaudeau e Dominique Maingueneau apontam que intertextualidade "designa ao mesmo tempo uma propriedade constitutiva de qualquer texto e o conjunto de relações explícitas ou implícitas que um texto ou um grupo de textos determinado mantém com outros textos. Na primeira acepção, é uma variante da interdiscursividade" (CHARAUDEAU; MAINGUENEAU, 2004, p. 288289). Ainda, sobre o caráter reflexivo e dialógico da literatura, Julie Sanders (2006, p. 14) lembra que:

texts feed off each other and create other texts, and other critical studies literature creates other literature. Part of the sheer pleasure of the reading experience must be the tension between the familiar and the new, and the recognition both of similarity and difference, between ourselves and between texts. The pleasure exists, then, in the act of reading in, around, and on (and on).

Já em relação à paródia, a pesquisadora Linda Hutcheon assevera que é uma "forma de imitação caracterizada por uma inversão irônica, nem sempre às custas do texto parodiado" (HUTCHEON, 1991, p. 17), havendo nela um distanciamento crítico, um julgamento de valor e a intenção de promover uma transcontextualização dos elementos da obra original. Nesse sentido, ela se alia a uma "auto reflexividade da arte moderna, ligada à intertextualidade e à transcontextualidade" (ALMEIDA, 2013, p. $4)$.

A paródia propõe uma nova visão sobre uma obra, sendo muito mais do que apenas uma referência a outros textos. Pode ser de uma obra em particular ou de um conjunto de convenções, não visando necessariamente uma ruptura ou o escárnio do texto (entendido num sentido amplo, como toda produção cultural com base na linguagem) parodiado, mas uma continuidade. Ela se coloca, desse modo, junto à tradição, de forma a combinar o novo e o antigo. 
Portanto, como argumenta Hutcheon, "não se trata de uma questão de imitação nostálgica de modelos passados: é uma confrontação estilística, uma recodificação moderna que estabelece a diferença no coração da semelhança" (HUTCHEON, 1991, p. 19). A paródia serve para ressacralizar ou dessacralizar uma obra ou um autor, ressaltando uma mudança, mas não uma submissão. Observa-se, nesse processo, uma relação estrutural e funcional de revisão crítica.

Nos termos de Genette, a teórica canadense vê na paródia uma relação estrutural ou formal entre textos que se inter-relacionam e, mais do que isso, buscam "parodiar outra obra (ou conjunto de convenções) e tanto um reconhecimento dessa intenção como capacidade de encontrar e interpretar o texto de fundo na sua relação com a paródia" (HUTCHEON, 1991, p. 34).

É necessário entender, ainda, a importância do leitor no processo de reconhecimento do texto com o qual a paródia dialoga. Conforme Marly Amarilha,

\begin{abstract}
a paródia se realiza pelo processo estrutural de intertextualidade. Em decorrência, exige do leitor sofisticado trabalho arqueológico de reconhecimento de um texto original ao qual o texto que imita se opõe e recria. No confronto que se instaura entre esses textos, o texto paródico ironiza o modelo do qual extrai sua própria existência [...] a paródia permite-se alusões, citações, inversões e assim, estabelece com o leitor cumplicidade a partir do que compartilham enquanto repertório cultural. A paródia convoca o leitor a estabelecer, com a brevidade de uma faísca, relações fundamentais para o avanço da narrativa. Apela, portanto, do ponto de vista cognitivo para a memória do leitor, instigando-o a acionar processo de leitura multidirecional, pois enquanto acompanha o desenrolar da história que lê, o leitor deve, continuamente, fazer inserções do patrimônio literário solicitado. O riso só chegará se as referências ao texto matriz forem reconhecidas, pois só chegamos ao deleite da imitação na paródia porque conhecemos os originais em que se baseia [...] nessa dinâmica realiza-se verdadeiro trabalho de coautoria, pois a convocação feita pela paródia depende da ativa participação da memória cultural e imaginária do leitor (AMARILHA, 2009, p. 66).
\end{abstract}

Já pensando na linguagem gráfica sequencial, Roberto Elísio dos Santos destaca que: 


\begin{abstract}
a paródia, como recurso humorístico usado nas histórias em quadrinhos, nasce da relação intertextual com outras linguagens da narrativa ficcional e da estilização feita da potencialidade expressiva da linguagem citada, esteja ela originalmente em um texto literário, cinematográfico ou televisivo. A adequação forçada de uma determinada linguagem ao potencial expressivo e narrativo dos quadrinhos já provoca o desvio necessário, o estranhamento caricatural, que pode gerar o riso (SANTOS, 2013, p. 8).
\end{abstract}

A originalidade de Mya Gosling reside no humor e, principalmente, no uso de elementos intertextuais para criar o efeito cômico. Em seguida, observaremos mais de perto como a cartunista realiza esse intento através da análise da história em quadrinhos intitulada The (Shakespearean) Monster Mash.

O entrelaçamento textual entre teatro, música e quadrinhos em The (Shakespearean) Monster Mash

No dia 31 de outubro de 2017 Mya Gosling publicou The (Shakespearian) Monster Mash, em homenagem a um hit de Halloween, The Monster Mash interpretada por Bobby Pickett (Robert George Pickett). Lançada originalmente como um single pela gravadora de Gary S. Paxton, Garpax Records, em agosto de 1962, foi inserida em um LP (Long Play ou disco de vinil) intitulado The Original Monster Mash que continha inúmeras faixas com a temática monstro. Tratava-se de uma novelty song ${ }^{1}$, uma divisão na música pop (como a ballad e a dance music), com intenção cômica ou nonsense, que alcançou grande sucesso entre 1920 e 1930 e ressurgiu durante as décadas de 1950 e 1960. É a música mais conhecida de Bobby Pickett e ficou do dia 20 ao dia 27 de outubro de 1962 (uma semana antes do Halloween, portanto) em $\mathbf{1}^{\mathbf{0}}$ lugar no Billboard Hot 100 (uma tabela que avalia as músicas mais vendidas no decorrer de uma semana). Ela chegou a ser banida do ar pela BBC na década de 1960 por ter sido considerada "muito mórbida" (ALLEN, 2017), foi relançada em 1973 (alcançando o 3ํㅣㅁ lugar nas

\footnotetext{
${ }^{1}$ Para ajudar o leitor, mencionamos aqui alguns exemplos retirados de uma lista com as cem melhores novelty songs: They're Coming to Take Me Away, Ha-Haaa, de Napoleon XIV; The Purple People Eater, de Sheb Wooley; Witch Doctor, de David Seville; Open the Door, Richard, de Dusty Fletcher. Disponível em: <https://digitaldreamdoor.com/pages/best_songs-novelty.html>. Acesso em 07/03/2018.
} 
paradas musicais no Reino Unido) e teve inúmeras versões covers, de grupos como The Beach Boys, Rush, Children of the Night, Bad Banners, Misfits e Smashing Pumpkins.

Ainda, no que concerne ao sucesso dessa canção, para se ter uma ideia, o Spotify, um serviço de streaming de música, podcast e vídeo lançado em 2008, contém não menos que 326 gravações de The Monster Mash, sendo considerada a música "mais sazonal do Spotify" (BUSKIRK, 2016) por ser escutada apenas na época do Halloween. Houve uma tentativa de dar continuidade ao sucesso da música através do lançamento de uma sequência, Monster's Holiday, em dezembro de 1962 e de um filme chamado Monster Mash (dirigido por Joel Cohen e Alec Sokolow) em 1995, no qual Pickett aparecia como o Dr. Victor Frankenstein. Além do mais, em 2014, o canal do YouTube, The Key of Awesome, atualizou a música de Bobby Pickett ao criar a Modern Monster Mash. Nela, outros monstros são revisitados, aparecendo personagens como Freddy Krueger, Hannibal Lecter, o boneco Billy de Jogos Mortais (2004), Michael Myers, da franquia Halloween (que teve início em 1978) e Samara Morgan de O chamado (2002).

Steve Greenberg, fundador da S-Curve Records, em um artigo denominado "50 Years of 'Monster Mash': the Story Behind the Halloween Hit" declara que a música composta por Pickett e Capizzi "has long since entered the pantheon of holiday evergreens, the Halloween equivalent of 'Rudolph The Red Nosed Reindeer' or 'Frosty The Snowman'" (GREENBERG, 2012). O autor ainda destaca que enquanto essas duas músicas desapareceram "into the mists of cultural obscurity" (GREENBERG, 2012), “Monster Mash” se tornou uma espécie de clássico, sobretudo, no contexto americano.

Para interpretar The Monster Mash, o cantor, compositor e ator (com aparições em It's a Bikini World (1967), Chrome and Hot Leather (1971), Deathmaster (1972) e Lobster Man From Mars (1989)), Bobby “Boris" Pickett (1938-2007), inspirou-se em personagens de filmes de terror de Boris Karloff (1887-1969) - famoso por seu Frankenstein (1931) - e Bela Lugosi (1882-1956) - conhecido por sua interpretação do Conde Drácula no filme de 1931. Desse modo, Pickett acrescentou na sua representação o endurecimento do movimento dos braços e das mãos para adicionar um 
efeito semelhante ao andar de Frankenstein. Já a melodia e parte da coreografia foram inspiradas fortemente nas músicas Alley Oop (sucesso de 1960), de Gary Paxton e Mashed Potato Time, de Dee Dee Sharp (que fez muito sucesso nas pistas de dança em 1962). Com efeitos sonoros pouco dispendiosos (realizados através de soluções simples, como o soprar de bolhas através de um canudo ou o arranhar de uma unha em uma tábua de madeira), a música apresenta sons borbulhantes de experimentos sendo realizados em um laboratório, caixões e portas rangendo, cadáveres e imitações vocais de monstros em segundo plano.

Sua letra narra a história de uma pessoa que estava trabalhando em um laboratório (um cientista possivelmente) até tarde da noite quando se deparou com um monstro (uma alusão a Frankenstein) que começou a dançar o Monster Mash e, em seguida, apareceram alguns vampiros, incluindo o próprio Drácula, além de fantasmas, zumbis e um lobisomem. Drácula quis saber o que aconteceu com o seu hit Transilvania Twist ao que lhe responderam que agora só se dançava o Monster Mash. O vampiro se juntou à banda e a música fez muito sucesso. No final, há um convite para que os vivos também dancem ao som de Monster Mash: "For you, the living, this mash was meant too/ When you get to my door, tell them Boris sent you/ Then you can mash/ Then you can monster mash/ The monster mash/ And do my graveyard smash [...] You'll catch on in a flash" (Songfacts, 2018).

$\mathrm{Na}$ versão shakespeariana, Mya Gosling recontextualiza/ recria/transpõe a letra de Pickett e Capizzi em 20 quadros: Brutus estava andando em sua tenda tarde da noite quando se deparou com o fantasma de César, coberto de sangue e feridas originadas de facadas, que começou a dançar o que a quadrinista chamou de Spectre Smash. Brutus esfrega os olhos, num gesto que expressa a sua descrença na visão que tem diante de si. O texto reforça essa ideia: “For a minute I thought, 'Hey, it's just my eyes. This Caesar, I am certain, met his demise'"'. No quadro seguinte, o fantasma revela que "Thou shalt see me at Philippi", numa citação direta à peça Júlio César, mais especificamente, à terceira cena do quarto ato.

Semelhante ao modo como Gosling retratou tal episódio nos quadrinhos, na peça shakespeariana, o fantasma de César aparece para 
Brutus em sua tenda, na véspera de sua batalha, para assombrá-lo. Como um mau presságio, a figura espectral prenuncia a morte de Brutus, numa espécie de vingança por seu assassinato.

Voltando à história em quadrinhos, o sexto quadro repete o refrão do terceiro, com a aparição de César dançando o Spectre Smash. A cartunista utiliza alguns recursos interessantes nestes dois quadros: ela cria uma espécie de jogral com a letra ao dividir os versos em duas cores - preto e cinza. Além disso, ela intercala os versos na cor preta, inserindo-os abaixo e no meio dos que estão em cinza. Para dar a ideia de que César está de fato dançando, Gosling o desenha três vezes no mesmo quadro em posições diferentes: à esquerda, com o olhar e os braços voltados para o mesmo lado; ao centro, com os braços erguidos para cima e o olhar voltado para o leitor; e à direita, com os braços e o olhar voltados para a mesma direção. Linhas cinéticas complementam o desenho e acentuam a mobilidade da personagem.

Logo depois, juntam-se a César os fantasmas de um rei dinamarquês, de dois príncipes e de um escocês encharcado de sangue. Um leitor familiarizado com as peças do bardo inglês (ou com a identidade visual criada por Mya Gosling para as personagens shakespearianas) reconhece sem demora os fantasmas do pai do Hamlet, dos sobrinhos de Ricardo III e do general Banquo. Ainda, é possível fazer essa mesma constatação a partir das falas desses espectros. Hamlet pai, por exemplo, grita: "Murder most foul!", fala retirada da quinta cena do primeiro ato de Hamlet, dita pelo próprio fantasma a seu filho Hamlet, quando este começa a explicar para o filho que o tio o assassinou com um veneno e exige que este o vingue. As crianças, por sua vez, entoam as palavras "death and despair", que ecoam a terceira cena do quinto ato de Ricardo III, quando as almas das vítimas de Ricardo vão ao seu encontro antes da batalha para lhe atormentar e lhe rogam que ele "despair and die". Vítimas desse vilão, os príncipes foram mortos a mando de Ricardo III, o que ocorre na terceira cena do quarto ato.

Vale ressaltar a criatividade da cartunista neste ponto da história: Gosling intercala a voz do narrador (Brutus) com a fala dos príncipes delimitada pelo balão para mostrar a simultaneidade das ações. Observe-se 
que os rabichos do balão de fala são abruptamente cortados/interrompidos pela narração, como se a autora tivesse apagado um pedaço dos mesmos. Já o terceiro fantasma, Banquo, apenas sacode seu cabelo ensanguentado, em uma alusão a uma fala de Macbeth na quarta cena do terceiro ato, "never shake thy gory locks at me". Ela é proferida durante o banquete, quando Macbeth avista o fantasma de Banquo, que toma o seu lugar na mesa.

No 13ำ quadro, o refrão "He did the smash!" pluraliza-se: “They did the smash!", embora mantenha o tamanho do $3^{\text {o }}$ e do $6^{\circ}$ quadro. Neste instante os cinco fantasmas juntam-se para dançar ao som dessa música pop: César e Hamlet pai estão virados para a esquerda, as crianças estão posicionadas ao centro e Banquo está voltado para a direita. Seus braços estão levantados e se agitam como se estivessem sendo movimentados. A seguir, Brutus, parecendo irritado, comenta que os fantasmas são péssimos convidados ("lousy guests") e que reclamam o tempo todo de seu descanso inquieto ("unquiet rests"), ou seja, de suas mortes truculentas. Ao seu lado está o espectro de Hamlet pai, com uma expressão séria, os braços levantados, como se estivesse, de fato, queixando-se de alguma coisa. O quadro subsequente traz uma informação importante: a noite avançou e festa terminou. Os fantasmas desapareceram assim que o galo cantou. Como aponta Monica-Maria Stapelberg, em seu livro Strange but True: a historical background to popular beliefs and traditions:

The central role the cock plays in folklore and myths worldwide is because of its loud crowing, its proud strutting, its aggressiveness, and its sexual ardour [...] in all cultures, malevolent forces and the appearance of spirits were considered particularly active at night, hence, they were known as the powers of darkness. Therefore, the cock's crowing at dawn, heralding daybreak, was seen as a welcome indication that these forces had been dispelled. Eventually, the belief arose that the bird was effective in exorcising evil, frightening away devils, warding off ghosts, and scaring away dangerous animals (STAPELBERG, 2014, p. 234).

A pesquisadora atenta para o fato de que Shakespeare reitera essa crença em Hamlet, quando o fantasma do pai de Hamlet desaparece repentinamente após o canto do galo: "It faded on the crowing of the cock $[\ldots]$ and then they say no spirit can walk abroad, [...] no fairy takes, nor 
witch has power to charm" (STAPELBERG, 2014, p. 234). Nessa história em quadrinhos, Gosling recupera a simbologia do galo e utiliza o animal para dar cabo dos fantasmas. Mais uma vez o refrão é alterado (Figura 5): “They did the smash" torna-se "They did the dash", uma brincadeira em relação à rapidez com que os espectros desapareceram.
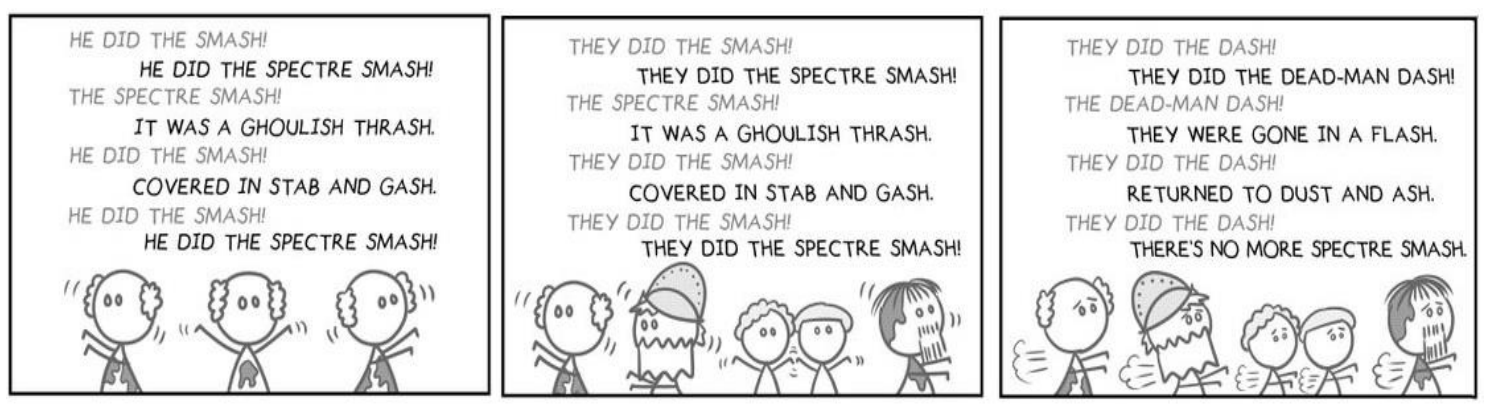

Figura 5: Refrões de The (Shakespearean) Monster Smash, HQ criada por Mya Gosling.

Fonte: <https:/goodticklebrain.com/home/2017/10/31/the-shakespearean-monstermash>.

Após o sumiço dos fantasmas, Brutus encontra-se sozinho. Ele está tenso e afirma que ainda não pôde acordar do pesadelo porque os fantasmas, antes de sair, previram que logo ele se juntaria a eles. Gosling divide essas informações em dois quadros: no primeiro, Brutus está só e desconsolado, já no segundo, como um lembrete do prenúncio, o fantasma de César está ao lado de Brutus, sorrindo e apontando para ele. O último refrão também é alterado, dessa vez, para incluir Brutus: a partir de sua morte, a personagem pode dançar a Specter Smash. Nesse sentido, a história termina de forma trágica, todavia, bem-humorada. Brutus canta: “Then I can Spectre Smash", "I'll do a ghoulish thrash", "My ghostly teeth I'll gnash", "I'll do the Spectre Smash". Assim como o Drácula foi incorporado à banda na música de Bobby Pickett, Brutus aparece no centro do quadro, unido aos outros fantasmas. Ele demonstra estar feliz, aparenta estar cantando a plenos pulmões. O último quadro é reservado ao espectro de Banquo, que canta as palavras finais de Monster Smash: "mash gooood". Até o balão de fala está em consonância com a música, visto que o rabicho 
aparece todo retorcido, como se estivesse ressoando o som. No canto inferior direito pode-se interpretar que ali está o desejo de Gosling aos seus leitores, pois se lê "Happy Halloween" retratado com uma tipografia distinta de todo o quadrinho.

Se, por um lado, o cenário é basicamente um fundo branco, por outro lado, chama a atenção nessa história em quadrinhos o modo como a autora enfatiza graficamente as reações e emoções das personagens, retratando com mais detalhes suas expressões faciais, que denotam medo, surpresa, descrença ou raiva, como se pode observar na Figura 6:

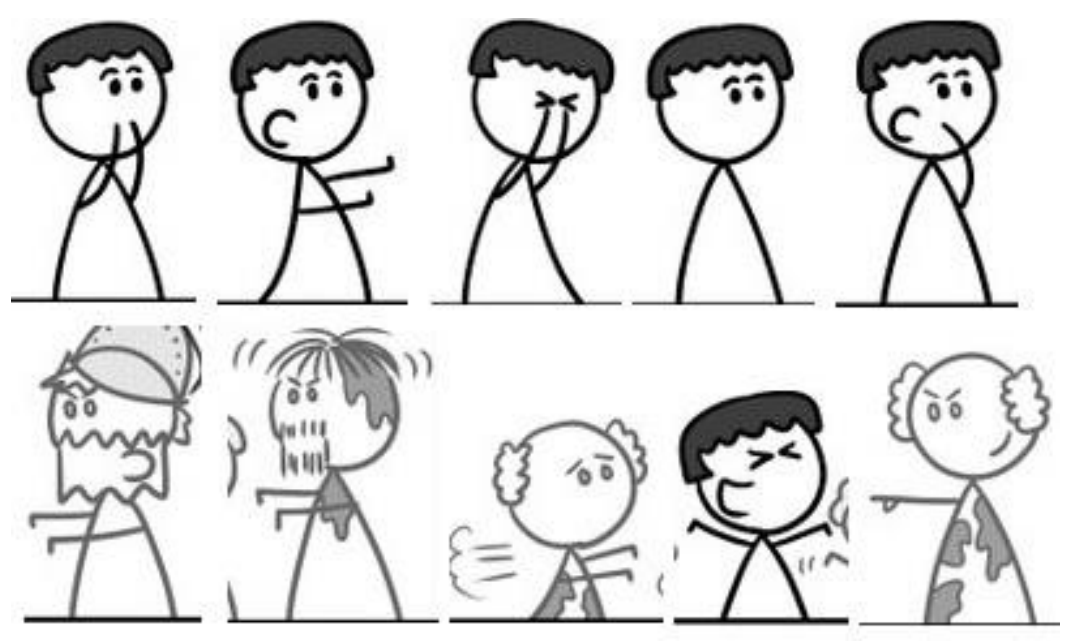

Figura 6: Expressões faciais e corporais das personagens em The (Shakespearean) Monster Smash.

Fonte: <https:/goodticklebrain.com/home/2017/10/31/the-shakespearean-monstermash>.

Também é importante mencionar o cuidado que a quadrinista tem em representar as suas personagens em diferentes tirinhas sempre da mesma maneira, criando, assim, uma identidade para cada uma delas e uma unidade para o seu trabalho. Coincidentemente, no dia 08 março de 2018 ela começou a exibir uma série de desenhos que explicam como ela faz para distinguir uma personagem da outra (Figura 7). 


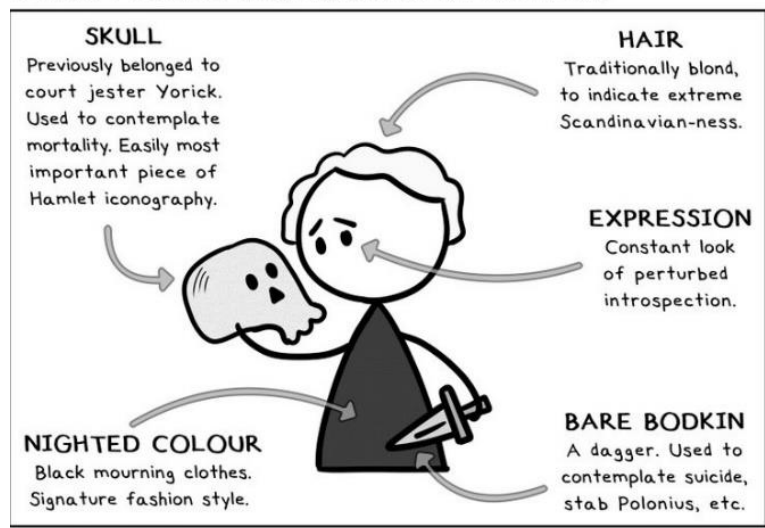

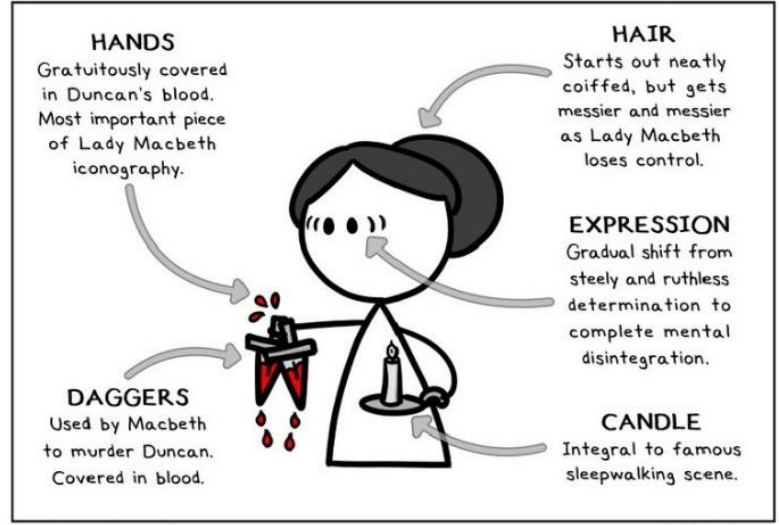

Figura 7: Gosling explica como trabalha a iconografia das personagens shakespearianas.

Fonte: $<$ https://goodticklebrain.com/>.

\section{Segundo Mya Gosling,}

When you're a stick figure artist, the main challenge you run into is how to differentiate various characters, because... well... they're all stick figures. Fortunately, many of Shakespeare's main characters have very distinctive characteristics and props that I can use. For the rest of the month we'll be taking a closer look at some of them, starting with The Big Guy [Hamlet] (GOSLING, 2018).

Outro detalhe a ser observado é a representação que Gosling faz dos fantasmas: enquanto Brutus, personagem viva, é desenhado na cor preta, os espectros aparecem na cor cinza, sinalizando sua incorporeidade, sua translucidez.

\section{Algumas considerações...}

O trabalho de Mya Gosling transita entre várias tradições e hábitos diferentes de consumo e apropriação cultural. A quadrinista cria uma relação íntima com as personagens e com o universo shakespeariano, estabelecendo um sentido de pertencimento; torna-o mais próximo, mais acessível. Tal feito é importante porque atualiza as obras do dramaturgo inglês, deixa as grandes tragédias (como por exemplo: Macbeth, Hamlet, Júlio César e Ricardo III, que apareceram no quadrinho abordado) mais 
ligadas às experiências dos leitores, mais no nível da leitura diária, do cotidiano.

Em The (Shakespearean) Monster Mash, Gosling faz uso de uma tradicional música de Halloween, lança mão da própria história da música pop norte-americana e brinca com essas tradições que estão enraizadas culturalmente, usando-as como pretexto para discutir, repensar ou mesmo como uma forma de abordar Shakespeare. Ela coloca em questão a imagem do criador e da criatura, ao trazer o universo de Frankenstein, do monstro e do humano, ao mencionar Drácula e o lobisomem. A cartunista transpõe essa temática para o âmbito shakespeariano (parodiando o dramaturgo inglês) e equaciona os fantasmas de Hamlet pai, Banquo, César e dos príncipes de Ricardo III com os monstros anteriormente mencionados. Realiza esse intento através de falas conhecidas das peças, das próprias personagens evocadas na narrativa e do contexto inicial da história: Brutus só em sua tenda. Deste modo, brinca e atualiza os questionamentos essenciais da obra shakespeariana sobre os limites da razão, da maldade, da ambição humana, sobre as fronteiras entre o bem e o mal, o ser humano e o monstro. Entre fantasmas, monstros fictícios, lendários, populares e personagens consagrados da literatura, a autora brinca com a grandiosidade e a banalidade da vida. A literatura é apresentada e compartilhada como uma experiência prazerosa, conectada às mais diversas práticas sociais, interagindo com outras mídias e outras linguagens artísticas.

Por fim, Gosling recupera a ideia do popular, algo que estava lá no teatro elisabetano ao qual pertenceu William Shakespeare e que se perdeu um pouco hoje. Ela não estabelece hierarquias entre as artes, entre uma certa erudição e o que é bem popular, entre o que é considerado cultura clássica e cultura de massa, entre o impresso e o digital, tentando mostrar como podem ser divertidas tanto a tradição literária quanto o que é mais da ordem do corriqueiro, do banal. Através dos quadrinhos, meio extremamente popular, com seus bonecos de traços simples, Mya Gosling coloca-se como uma mediadora entre os leitores de quadrinhos digitais, usuários de redes sociais e leitores de Shakespeare, garantindo espaço para um profícuo debate, com novas e surpreendentes interpretações. Foi 
possível observar como o uso criativo das novas tecnologias possibilita uma visão crítica da literatura, da música e dos quadrinhos, além de criar um diálogo ou um entrecruzamento de fronteiras entre essas diferentes mídias.

\section{Referências}

ALLEN, Jeremy. "8 songs banned by the BBC for the strangest of reasons". Artigo publicado em 26/10/2017. Disponível em: https://www.bbc.co.uk/music/articles/46f837da-9ffa-494d-94e7c7ffb0781bea Acesso em: 07 mar 2018.

ALMEIDA, Maiara Alvim de. "Leituras de Shakespeare a partir de Neil Gaiman - algumas considerações sobre graphic novels e paródia". Anais das 2as Jornadas Internacionais de Histórias em Quadrinhos, ocorridas entre 20 e 23 de agosto de 2013 na Universidade de São Paulo. Disponível em: <https://goo.gl/yavU1f>. Acesso em: 28 mar 2018.

AMARILHA, Marly. "História em quadrinhos e literatura infantil: a paródia na formação do leitor". Revista Educação em Questão, Natal, v. 36, n. 22, p. 56-73, set./dez. 2009. Disponível em: https://periodicos.ufrn.br/educacaoemquestao/article/viewFile/3967/3234 Acesso em: 27 mar 2018.

BONA, Rafael Jose. "Consumo, quadrinhos e cinema: a transposição do filme De volta para o futuro para as narrativas gráficas da Turma da Mônica". LUMINA: Revista do Programa de Pós-Graduação em Comunicação da Universidade Federal de Juiz de Fora, v.11, n.3, set/dez 2017. Disponível em: https://lumina.ufjf.emnuvens.com.br/lumina/article/download/593/531 Acesso em: 30 mar 2018.

BUSKIRK, Eliot. “The 'Monster Mash' Is The Most Seasonal Song on Spotify". Artigo publicado em 28/10/2016. Disponível em: https://insights.spotify.com/br/2016/10/28/they-did-the-monster-mash

Acesso em: 07 mar 2018.

CHARAUDEAU, Patrick; MAINGUENEAU, Dominique. Dicionário de Análise do Discurso. São Paulo: Contexto, 2004.

GOSLING, M. Good Tickle Brain: a mostly Shakespeare webcomic. Disponível em: http://goodticklebrain.com/ Acesso em: 24 fev 2018. 
GREENBERG, Steve. 50 Years of 'Monster Mash': The Story Behind the Halloween Hit. Artigo publicado na Billboard, no dia 31/10/2012. Disponível em: https://goo.gl/GGv9xP Acesso em: 16 mar 2018.

HUTCHEON, Linda. Uma teoria da paródia: ensinamentos das formas de arte do século XX. Trad. Teresa Louro Pérez. Lisboa: Edições 70, 1991.

KRISTEVA, Julia. Introdução à semanálise. Tradução de Lúcia Helena França Ferraz. São Paulo: Perspectiva, 1974.

PEREIRA, Leonardo Vinicius Macedo. Ai de ti, Yorick Brown: a paródia do drama shakespeariano como evolução das histórias em quadrinhos. Dissertação apresentada ao Programa de Pós-Graduação em Letras da Universidade Federal de Viçosa, Viçosa (MG), 2015. Disponível em: <https://goo.gl/mqJVvp>. Acesso em: 08 mar 2018.

RAJEWSKY, Irina. "Intermidialidade, intertextualidade e 'remediação'". Uma perspectiva literária sobre a intermidialidade. Trad. Thais Flores Nogueira Diniz e Eliana Lourenço de Lima Reis. In: DINIZ, Thais Flores Nogueira; REIS, Eliana Lourenço de Lima (Orgs.). Intermidialidade e Estudos Interartes. Desafios da arte contemporânea. Belo Horizonte: Editora da UFMG, 2012.

SANDERS, Julie. Adaptation and Appropriation. London and New York: Routledge (The New Critical Idiom), 2006.

SANTOS, Roberto Elísio dos. "Humor, metalinguagem e intertextualidade nas histórias em quadrinhos de Mauricio de Sousa". Anais das 2as Jornadas Internacionais de Histórias em Quadrinhos, ocorridas entre 20 e 23 de agosto de 2013 na Universidade de São Paulo. Disponível em: <https://goo.gl/K39skw>. Acesso em: 24 mar 2018.

SONGFACTS. Monster Mash by Bobby "Boris" Pickett \& The CryptKickers. Disponível em: http://www.songfacts.com/detail.php?lyrics=6618 Acesso em: 08/03/2018.

\section{Resumo}

Neste artigo buscamos analisar The (Shakespearean) Monster Mash, uma paródia em quadrinhos criada por Mya Lixian Gosling a partir de personagens de quatro peças shakespearianas - Júlio César, Hamlet, Macbeth e Ricardo III - e da música The Monster Mash, composta por Leonard Capizzi 
e Bob Pickett. Nessa perspectiva, usaremos como base reflexões sobre transposição intermidiática, intertextualidade e paródia por autores como Irina Rajewsky, Julia Kristeva e Linda Hutcheon. Observaremos como a cartunista articula sua narrativa gráfica sequencial a fim de obter o efeito cômico.

Palavras-chave: Quadrinização shakespeariana; Monster Mash; Mya Gosling.

\begin{abstract}
In this article we seek to analyze The (Shakespearean) Monster Mash, an online comic book parody created by Mya Lixian Gosling from characters of four Shakespearian plays - Julius Caesar, Hamlet, Macbeth and Richard III - and the song The Monster Mash, composed by Leonard Capizzi and Bob Pickett. From this perspective, we will use reflections on medial transposition, intertextuality and parody by authors such as Irina Rajewsky, Julia Kristeva and Linda Hutcheon. We will observe how the cartoonist articulates her sequential graphic narrative in order to obtain the comic effect.
\end{abstract}

Keywords: Shakespearean comics; Monster Mash; Mya Gosling. 